\title{
Las fiestas de vecindad en la Palma de Mallorca del siglo XIX
}

GABRIEL LLOMPART

Palma de Mallorca

RESUMEN

A través de documentación municipal - solicitudes de permisos para la celebración de fiestas vecinales en Palma de Mallorca- entre 1860 y 1918, se analizan elementos festivos de vecindad, algunos de ellos vigentes desde época medieval y otros de nueva incorporación, dibujando así una época y una sociedad.

Palabras clave: Palma de Mallorca, Fiestas vecinales, Documentos municipales, Ritualidad, Mundo urbano, Siglos XIX y XX.

\section{SUMMARY}

By searching city council records for applications for the holding of neighborhood festivals in Palma de Mallorca from 1860 to 1918, the author analyzes festive elements of neighborliness at the time. While some of these elements dated to the Middle Ages and others were new, all reveal the contours of an era and a society.

Key words: Palma de Mallorca, Neighborhood Festivals, City Council Records, Ritual, Urban World, $19^{\text {th }}$ and $20^{\text {th }}$ centuries.

Entre las fiestas populares propias del Antiguo Régimen, cuyo hito podemos situar en la Guerra de la Independencia, y las fiestas populares actuales, más o menos articuladas (o desarticuladas) después de la Guerra Civil de mediados del siglo $\mathrm{xx}$, parece haber existido un canon $\mathrm{O}$ módulo propio del siglo XIX que queremos documentar en estas páginas sobre la base de un tipo de documentación inusual pero preciso y expeditivo: las solicitudes de permiso municipales.

Un puñado de solicitudes de este tipo procedentes del Archivo Municipal de Palma de Mallorca, facilitadas por el Dr. Manuel Oliver Moragues, que muestran un modelo madurado y bien construido, van a servirnos de pautado para la reconstrucción sociológica, amparados por la bibliografía existente sobre la fiesta medieval y barroca (Mulet 1956; Llompart

RDTP, LX, 2 (2005): 181-190 
1961; Ensenyat 1975; Durán 1989), y teniendo presentes los ecos de la tradición oral por lo que hace a las celebraciones del siglo $\mathrm{xx}$, de cuyo testimonio sale garante personal la experiencia de vida ciudadana del firmante.

Las solicitudes en cuestión forman dos grupos: el de los festejos de la década de 1860 y el de la década de 1880 . La presentación es en folios del llamado papel sellado o papel de Estado con sello marcado en dos reales el de 1863 y 1865, y en setenta y cinco céntimos de peseta los de 1883. Mención aparte merece el legajo de las fiestas de Establiments de 1918 que consiste en un manojo de siete cuentas presentadas al Ayuntamiento. Las signaturas de estos tres bloques son respectivamente: Archivo Municipal de Palma (AMP) Legajo 19659 (Permisos para diversiones públicas 1863 a 1865). AMP, Legajo 1513. Expediente 18635 y, por último, AMP. Fondo Establiments.

La dirección va encaminada al M.I.Sr.; Excmo., Alcalde, Alcalde Constitucional, Presidente del Ayuntamiento y lleva al margen, como es de rigor, la autorización firmada y fechada. En algún caso, condicionada y anotada.

El peticionario se presenta de ordinario como un ciudadano más, ofreciendo sus señas personales, otras veces lo hace como mayordomo de una cofradía o "Concordia", mando militar o custodia de iglesia.

El grueso de las solicitudes de 1865 es de 9 piezas ordinarias, a las que hay que adjuntar algunas de índole excepcional, en este caso: dos permisos para un festival de gimnasia, firmados por un tal profesor monsieur Arnaud Bateaux, cuyos niños o alumnos debían realizarlo al aire libre en el Molinar y en las Figueres Baixes (El Secar de la Real) en 1865; un pasacalles de la banda de música del Regimiento de Infantería núm. 13 en el carnaval de 1863 (de las 14 a las 21 horas), y una fiesta de Carnaval propuesta por la barriada de la Herrería para febrero de 1863 , que consiste en una hoguera, un baile y la actuación de una banda de guitarra. Esta proposición es la que tenemos figurada en un cuadro local decimonónico de Gaspar Reinés (1807-1885) con ejemplares en el Museo de Lluc y en la Colección Massutí de Palma. Las solicitudes de 1883 son en número de 14.

El espacio geográfico y poblacional corresponde en general al casco viejo, amurallado todavía, nombrándose las calles y aludiendo al barrio. Se trata de fiestas de verano, patronales o de templos o capillitas de calle de advocación religiosa. Por extensión, también aparecen localidades del área municipal fuera del casco antiguo como son Génova, la Vileta, San Bernat y San Jordi del Prat... El único barrio extramuros adosado que se nombra es el de Santa Catalina. 
FIESTAS DE CALLES Y BARRIOS DE LA DÉCADA DE 1860:

Calle Sindicat, en el mes de julio, dedicada a Santiago.

Calle Camaró, en el mes de julio, dedicada a Santa Ana.

Plaza de Santa Magdalena, en el mes de julio, dedicada a la beata Catalina Tomás.

Calle de Santa Clara, en el mes de agosto, dedicada a Santa Clara.

Calle de San Matgí, en el mes de agosto, dedicada a San Magín.

Calle de San Matgí, en el mes de julio, dedicadas a San Magín y a la Virgen de la Esperanza.

Barriada del Secar de la Real, en el mes de agosto, dedicada a San Bernardo.

Calle del Pes de la Palla, en el mes de noviembre, dedicada a la Sangre de Cristo (capillita callejera).

Calles del Pas den Quint y San Nicolás, en noviembre, dedicada a la Virgen de la Esperanza (capillita callejera).

Fiestas DE CALles y BARRIADAS DE LA DÉCADA DE 1880:

de la Concepció, en el mes de julio, dedicada a la Purísima Concepción.

de Cavallería, Ermitaño, en julio, dedicada a la Preciosa Sangre.

Barrio de la Calatrava, en julio, dedicada a San Cristóbal.

dels Oms. en el mes de julio, dedicada a la Virgen del Carmen (proximidad del convento homónimo)

de Pou, en Santa Catalina, en julio, dedicada a la Virgen del Carmen (con vecindad a otro convento homónimo)

de San Miguel, en el mes de julio, dedicada a Santiago.

Barriada de Son Anglada, en el mes de julio, dedicada a San Roque.

Barriada de Sant Jordi, en el mes de julio,

Monasterio de Santa Magdalena, en julio dedicada a Sta. Catalina Tomás

Barriada de Génova, en el mes de septiembre, dedicada al Salvador, titular de la parroquia

Calle G. Barceló y Calle San Pedro, en el mes de junio, dedicada a San Pedro.

El legajo correspondiente a las fiestas de San Jaime de la localidad de Establiments, de fecha más reciente (1918) me han permitido aplicar a las cuentas, retiros de memoria personal:

- Honorarios de la banda de música, 80 ptas.

- Honorarios de gaita y tamboril, 32 ptas.

- Transporte de los músicos en carruaje, 25 ptas. 
- Transporte de mirto y chopo, sillas, tablado, faroles 40 ptas.

- Comida y bebida de operarios de alumbrado y de gaiteros, 15 ptas.

- Hilo, papel, cintas, clavos, premios, carburo, ensaimadas, tabaco, refrescos, mantenimiento de sillas (cien unidades) 85 ptas.

- Alquiler de 60 luces de acetileno, una máquina y jornadas del técnico 33 ptas.

- Servicio religioso 25 ptas.

- Alquiler y reparación de sillas 6 ptas.

- Premios (4 conejos, 2 pollos) y jornales de organización de las carreras de a pie 46 ptas.

Estas cuentas nos permiten atisbar el anclaje de la fiesta de una localidad campesina cercana a la capital en el bumus del pasado. De hecho, la fiesta patronal rural medieval estaba integrada por una triada: el oficio religioso del día, el baile de la vigilia (revetla, velada) y las carreras a pie y a caballo.

En estas cuentas de Establiments aparecen los adornos vegetales, los premios de conejos y volatería, el mantenimiento y paga de los gaiteros o músicos tradicionales, los premios más sencillos (pañuelos, tabaco, ensaimadas) que se brindaban a los corredores y corredoras atados en el extremo de una caña verde que el primero en llegar a la meta aprehendía de un violento tirón. Todos estos elementos ya se hallan en los libros de clavería de los municipios medievales.

El gasto, que ha aumentado, y la comodidad se valoran ahora mejor con la abundancia relativa del alumbrado a base de acetileno y la presencia de las sillas de alquiler. Aquí se ha mejorado pero si las cuentas del año 1918 nos hacen sentir el adelanto, las de la instalación eléctrica de 1936, si las tuviéramos, nos mostrarían todavía un mayor progreso. Lo digo por cuanto he tenido amistad con un electricista empleado en una modesta compañía dedicada a preparar fiestas patronales de verano durante la II República Española y, aunque un imprevisible accidente me impidió en su día entrevistarle, recuerdo bien cómo explicaba el montaje de luces en torno a un tablado o una pista improvisada en la que tenía lugar el baile tradicional o moderno que acondicionaba profesionalmente. Obvio es decir que en las solicitudes de fiestas del siglo XIX sólamente se interesaba autorización para la danza folklórica de guitarra o gaita y tamboril. El siglo xx dio un paso adelante al divulgar el baile de salón.

El hecho de que gran parte de los solicitantes se autodenominen mayordomos o clavarios (por claveros, mallorquinismo) nos sugier el que los mencionados festejos los organizara un gremio de menestrales, concretamente el que radicaba en una determinada calle principal y aleda- 
ños: Dichos gremios desde el siglo xv celebraban sus fiestas en las capillas propias que tenían en parroquias y conventos a las que concurrían colegialmente tras de su estandarte, que dejaban plantado simbólicamente ante su casa gremial. Cuando la supresión de los gremios a principios del siglo XIX dejó las fiestas colgadas en el aire, el vecindario tuvo que organizarse y lo hizo remedando el esquema que los gremios habían dejado impreso en la memoria colectiva.

A primera vista tres de los festejos arriba citados seguían siendo organizados por los mencionados gremios: el de San Pedro, patrono de los pescadores, en la parroquia marinera de Santa Cruz, que ha pervivido hasta hoy; el de San Cristóbal, patrono de los curtidores, en el barrio de Calatrava (localizado en la iglesia de Santa $\mathrm{Fe}$ ) y por último, el de los alfareros, en el barrio llamado Sa Gerrería, con la Trinidad por patrona, por aquello de que "Al principio Dios creó al hombre del barro de la tierra" y que centraban su culto en el templo de Trinitarios, hoy San Felipe Neri.

A este sistema organizativo se adhirieron evidentemente las localidades del Llano de Palma, crecidas en torno a una iglesia, tal es el caso de Génova, la Vileta Establiments y Sant Jordi. Estos núcleos de población estaban en proceso de desarrollo y devinieron parroquias en el decurso del siglo XIX. Hasta entonces las circunscripciones parroquiales intramuros de la ciudad se alargaban hasta los límites de los pueblos de la Mallorca profunda. Se comprende por tanto que estas comunidades in fieri acelerado adoptaran el modelo de festejo propio de los gremios y que, a su vez, tenía su paralelo en el que usaban las parroquias rurales de las villas foráneas.

Las fiestas de calle que hemos mencionado - tipo Sindicato, Camaró, Santa Clara, San Magín, Peso de la Paja, Caballería, San Miguel, Pou, etc.se repliegan sobre sus iglesias y conventos e incluso cuando estos no existen sobre capillitas de muro y partiendo del oficio religioso configuran el festejo anual a la manera gremial. Si los menestrales pagaban una cuota para mantener sus derechos y obligaciones en vez de la colectividad laboral ahora los vecinos serán los que pagarán su cuota durante un año, el que media de fiesta patronal a fiesta patronal, y se autodenominarán "confiares" (cofrades) como sus directores se llamarán mayordomos, claveros y sobre posats o vocales. Pero no nos llamemos a engaño, se trata de una comisión de festejos, no más. Pero tampoco menos. Sobre todo si nos fijamos en la relación de solicitudes de los años 1860. En la mayoría de ellas se menciona el paseo de un buey por la barriada. Un poeta local contemporáneo, refiriéndose a la fiesta de San Cristóbal, describe un paseo a mediodía por las callejas y la presencia en el aire de 
subrayados olores característicos: el del guisado de carne (estofado) y el de la canela del postre (menjar blanc). Porque todo el barrio seguía la misma minuta: el guisado de carne de buey elaborado con la pesada repartida a cada cofrade y la crema de leche en la que se reblandecía la "Cocada" a que tenía derecho todo cofrade el día del Santo. La minuta proviene también del mundo gremial. En tiempos pasados la carne era un plato de lujo. Si una colectividad podía asegurar el consumo de una res - puesto que la carne no se podía conservar mucho tiempo- se la sacrificaba sin más, presupuesto naturalmente el permiso de la autoridad que debía velar por el censo de las bestias de matanza.

Un apartado de la solicitud de celebración de festejos se refiere a la llegada del buey que el vecindario había ido pagando de consuno a lo largo del año y que después del paseo de rigor ingresaba en el matadero. Quisiera subrayar la relación existente entre la llegada esperada y alborozada del buey, al principio de los festejos, que constituye un peligro en su desfile por el barrio, dado el talante de la juventud local que lo hostigaba y martirizaba (de donde el origen de las dichosas corridas de toros, según intuye cualquier lector inteligente de las Cantigas de Alfonso $\mathrm{X}$ el Sabio). Esta entrada aparatosa del buey, hito de la fiesta patronal, se conserva hoy en un sólo lugarejo de la sierra de Mallorca pero, durante un tiempo estaba generalizada. Basta consultar vieja bibliografía de los pueblos del Prepirineo catalán para advertir la desinformación existente en gran parte de la opinión pública catalana acerca de la pretendida repugnancia del pueblo catalán hacia las corridas de toros. El paseo estaba generalizado. $\mathrm{Y}$ a propósito de la palabra corrida que es corriente en nuestras solicitudes y es una mala traducción del catalán o mallorquín correguda, nótese que se suele referir a las carreras a pie y a caballo que eran un número importante de los festejos medievales. Pero al mismo tiempo este término corrida, se prodigó con la aparición de la prensa y la edificación de las plazas de toros, efímeras o de fábrica. La costumbre medieval en las villas era reunirse la población después de la misa mayor en la calle o sitio conocido como el cos (cfr. corso, en italiano; coso en castellano) en donde se tenían las pruebas de velocidad a pie y a caballo, de hombres, mujeres y niños...

En nuestras solicitudes nos encontramos con carreras de caballos en los barrios próximos a la muralla y en los caseríos - los del centro urbano o no tenían caballos o no tenían espacio o carecían de afición-. Destacan: los barrios de Santa Cruz, de la Calatrava, de Sant Jordi, de Santa Catalina y de Establiments.

Por lo que se refiere a las carreras a pie ya hablamos de ellas al comentar el legajo de los festejos de Establiments de 1918. En estos meses 
de verano hacia el mediodía pegaba un sol de fuego cuando los corredores se disputaban las cañas verdes en cuya punta se colgaba el premio, que oscilaba entre un par de alpargatas o pañuelos y un pollo o un conejo. En el año 1935 en que mi padre fue clavario de los festejos de San Roque en Son Roca, en los aledaños de Palma, recuerdo que los niños tuvieron como premios máximos los mismos que los mayores pero en talla enana: el pollo era un kik y el conejo un conill de rata. Desconozco de dónde se sacaría la ocurrencia; acaso fuera una humorada suya.

La decoración del espacio en la fiesta local parte de la tradición de esparcir mirto troceado por las calles con la finalidad de refrescar y perfumar el ambiente. Las ramas verdes se mantienen enhiestas apoyadas en los muros de las viviendas junto a los tiestos regados y mimados todo el año por las amas de casa. Al verde rústico se suma el papel de colorines urbano que se coloca por encima de las calles como una marea de fantasía que el aire torna sonora. Se llaman paperines en el argot local. He alcanzado a ver todavía dos grandes banderas que con efigies o cruces alusivas presidían la calle principal de la fiesta de barrio: La del barrio de San Juan de Malta en el puerto de Palma y la de la Virgen del Carmen, que ondeaba en la calle de los Olmos. Tenían una hechura especial, más que de bandera, de estandarte y más que de estandarte de tela pintada.

El clima mediterráneo hace que la hora mejor para salir al aire libre y disfrutar del fresco haciendo tertulia comiendo chucherías y tomando algún refresco sea la noche. De ahí que en la Edad Media el vocablo utilizado para significar los festejos en la isla de Mallorca fuera el de "luminàries" que se disponían sobre tederos en forma de haces de ramas ardiendo, o bien se componían en las fachadas mediante faroles, vasos y caracoles cebados con aceite y mechas.

Las danzas populares se solían tener a la caída de la tarde y noche después de algún ejercicio religioso que podía consistir en la asistencia a la Salve cantada, de la hora litúrgica de Completas o, a lo mejor, en una procesión. Las danzas populares son llamadas en concreto “boleros" en algunas solicitudes.

Sin música no hay fiesta. La pareja de músicos conocida desde el siglo XIV como juglares consta de un gaitero y un tamborilero con pito. Estos son los números que amenizan los paseos nocturnos y las danzas propias de la fiesta de la vecindad. Se les contrataba en el campo donde ejercían ordinariamente como pastores; yo con frecuencia en las noches de verano he oído todavía los ecos de sus tocatas mientras guardaban el ganado a pocos kilómetros de la ciudad de Palma.

Uno de los números que se nombran en las solicitudes es la cucaña. 
Hoy en día ha desaparecido del mapa, salvo en la fiesta de San Antonio de Viana de Pollensa, donde se corta un pino y traslada a la villa, se limpia el tronco y se dispone con sus volátiles en la punta, en medio de la plaza del lugar. El espectáculo está servido.

Sólo se da un ejemplo en que se pida permiso para soltar un globo aerostático, permiso que viene denegado por cuanto en el estío la cosecha de cereal está por recoger o el fondo de rastrojos se juzga potencialmente inflamable. De hecho en la Edad Media la quema de rastrojos exigía permiso municipal, caso por caso, e información previa al vecindario.

Únicamente en algunos documentos se mencionan los fuegos de artificio y si acaso el encendido de bengalas en momentos cruciales de la danza que he visto usar antes de la guerra civil para potenciar momentáneamente la pobreza lumínica del tendido eléctrico ocasional.

Un juego que en el siglo XIX se solicita es el apedreamiento del gallo. Este desaparece en el siglo Xx. Otro juego que no aparece en el XIX y sí en el $\mathrm{xx}$ es el de las carreras de bicicletas o, por lo menos, las carreras de cintas en bicicleta que se han perdido en el xxI. Se comprende perfectamente que el ensartado y desarrollo de las cintas de colores en bicicleta es una variante del mismo juego practicado antes a lomos de caballerías, como se usa en la isla de Menorca y que ya desapareció entre nosotros. La chiquillería se entretenía con los polichinelas.

No hay ningún rastro en estos permisos de la presencia de vendedores ambulantes y feriantes, pero no cabe duda de que estos concurrían por la cuenta que les traía. Hay dos fiestas de carácter de romería que aparecen en las revistas ilustradas de comienzos del siglo $\mathrm{xx}$ donde se representan las casetas y puestos de feriantes: se trata de las fiestas de San Bernardo de la Real y de San Marcial, en las cercanías de Marratxí. San Bernardo era la gran atracción de los habitantes de Palma a fines del verano. Se decía del calor veraniego: Sa monja l'encen i es frare l'apaga. (La monja, es Santa Margarita; el fraile, San Bernardo. Siempre en clave popular, porque propiamente hablando ni Santa Margarita era monja, ni fraile San Bernardo sino monje). En cambio San Marcial, a primeros del verano, atraía a la payesía de la Mallorca interior, que a menudo pasaba la noche al descampado. Este es el fósil que dejó en la isla la tradición medieval de concurrir a la vigilia del santo (la vetla, la revetla). San Marcial tenía pinturas en muchas parroquias payesas y las plegarias tradicionales le veneran como abogado de algunas dolencias menores. En general, hay que decir que las estampas devocionales siempre se expendían en los templos, las medallas se encargaban a los plateros y las golosinas se reducían a frutos secos del país, como almendras, en forma de confites, o turrones, o de importación como las avellanas. Añádase la fruta fresca del 
tiempo, sobre todo los membrillos de San Bernardo. El agua natural del siglo XIX pasó a gaseosa en el Xx y a Coca-cola en el XXI. Siempre ha tenido la competencia del vino.

Para terminar, digamos que los festejos paralelos en la actualidad siguen con el mismo perfil aunque son objeto de modificaciones y experimentos que no permiten pronosticar la permanencia de un mismo modelo en un futuro próximo.

\section{APÉNDICE}

\section{Muestra de solicitud de permiso municipal. Muestra I}

Excmo. Señor:

Francisco Barceló y Cantallops de este vecindario, calle de la Alfarería núm. 30, según cédula núm. 2.284, que pone de manifiesto y retira, como mayordomo de la fiesta callejera dedicada a la Santa Trinidad que ha de tener lugar en la calle del Socorro y contiguas.

a V. S. suplica se digne, si lo tiene a bien, conceder permiso para celebrarla en los días 14, 20, 21 y 22 del corriente, esto es, el día 14 colocar las banderas con música, levantar dos tablados, uno en la calle del Socorro esquina a la de la Alfarería y otra en la de la Alfarería, esquina a la de San Agustín, para tocar las mismas en los días señalados y el 22 corrida de muchachos, guardando al efecto todas las reglas del decoro y orden.

Gracia que espera merecer de la notoria rectitud de V.E., cuya vida que Dios M. a. Palma, 11 de mayo de 1883.

Excmo. Señor Alcalde Constitucional de esta capital.

FRANCISCO BARCELÓ.

\section{Muestra II}

Excmo. Sr.

Ramón Mas y Obrador, de este vecindario. Arrabal de Santa Catalina, calle de Pou núm. Uno, según cédula núm. 29161 que pone de manifiesto y retira, como mayordomo de la fiesta callejera dedicada a Nuestra Señora del Carmen que ha de tener lugar en la calle de la Purciana y contiguas.

a V. E. suplica se digne, si lo tiene a bien, concederle permiso para celebrarla en los días 19, 21 y 22 del corriente, esto es, el día 15 colocar las banderas con música, levantar dos tablados para tocar la música en los días señalados, el uno en la calle de la Purciana esquina a la de Pou y el otro bajo en la plazuela que forma la calle de la Fábrica y de Hornabeque, el 21 hacer teresetas en la calle de la Industria y en la de la Barrera y fuegos artificiales en la planada de la calle de la Ronda de Poniente y corrida de muchachos y hombres, algunos dentro de sacos, e iluminar las calles con reverberos y algunos festés, guardando al efecto todas las reglas del decoro y orden.

Gracia que no duda [etc]. 


\section{Muestra III}

Excmo. Sr.

D. Pedro Font, custos de la iglesia del Pla de Sant Jordi a V. R. respetuosamente expone que desea se le conceda permiso para celebrar una fiesta rústica y campestre en dicho puesto los días 28 y 29 de este mes, consistente en baile de boleros al estilo del país, corridas de caballos y hombres al estilo del país y la diversión conocida con el nombre de Pegá en es gall, también al estilo del país, todo guardando el orden y compostura necesarios en estos casos.

Gracia que V.E. espera será atendida.

Palma 24 de julio 1883

Excmo. Sr. Alcalde de esta ciudad.

JOSE CABRER M. M.

\section{BIBLIOGRAFÍA CITADA}

DURÁN DAMIÀ. 1989. Roda de folklore pagés. Manacor.

Ensenyat Estrany, Bartolomé. 1975. Folklore de Mallorca. Palma de Mallorca.

LLOMPART, GABRIEL. 1961. "Fiestas populares y bandas de juglares en el medievo mallorquín". BSAL 33: 479-496.

MULET, ANTONI. 1956. El baile popular en Mallorca. Palma de Mallorca. 